\title{
Uma narrativa atualíssima
}

\author{
Benito Martinez Rodriguez
}

Todo abismo é navegável a barquinhos de papel.

Guimarães Rosa, Tutameia

A leitura do romance Navios iluminados, de Ranulfo Prata, que reaparece em nova edição (Edusp), a quinta desde sua publicação em 1937, produz uma peculiar impressão de atualidade, apesar das quase nove décadas que nos separam do quadro cronológico de seu entrecho narrativo, que se situa na segunda metade da década de 1920.

De fato, o leitor sai das páginas desse romance com uma perturbadora sensação de familiaridade, ainda que não tenha maior experiência de leitura da produção ficcional do próprio Ranulfo Prata ou de outros de seus contemporâneos de pouco menos de um século atrás.

No meu caso, pareceu-me inevitável o paralelo com relação a certa linhagem da ficção contemporânea, que pode ser retraçada de modo mais imediato a Cidade de Deus (1997), o romance de estreia de Paulo Lins. ${ }^{27}$ Reconhecidas as diferenças mais óbvias entre o tom brutalista e o ritmo trepidante deste, que contrastam vivamente com as notas líricas e o andamento tardo mais de uma vez apontados pelos comentaristas de Navios iluminados, bem como as grandes diferenças entre a metrópole carioca e a cidade do litoral paulista na virada para a década de 1930, seria possível encontrar pontos de afinidade nada irrelevantes entre tais narrativas.

Trata-se, em ambos os casos, de romances que se colocam o desafio de representar os destituídos de voz na cidade letrada. Para tanto, ainda que em fatura diversa, seus autores mobilizam uma série de elementos extraídos do que Roberto Schwarz, ${ }^{28}$ referindo-se à obra de Lins, caracterizou como "parceria com a enquete social", em linhagem que entronca, entre outras, na tradição do Naturalismo do século XIX.

27. Lins, Paulo. Cidade de Deus. São Paulo: Companhia das Letras, 1997.

28. Schwarz, Roberto. "Uma aventura artística incomum". Mais, Folha de S.Paulo, 7 set. 1997. Posteriormente incluído em Sequências brasileiras. São Paulo: Companhia das Letras, 1999. 
Se são conhecidos os vínculos do trabalho de Lins com o projeto "Crime e criminalidade no Rio de Janeiro", coordenado por Alba Zaluar e em cujas fontes está parte substancial dos materiais posteriormente refundidos em sua obra ficcional, no caso de Ranulfo Prata a atividade contínua como médico radiologista, com especial interesse nas doenças do pulmão, em clínica particular, na Santa Casa de Misericórdia de Santos, e sobretudo no Ambulatório Gaffrée-Guinle, instituição dedicada ao atendimento dos empregados da Companhia Docas de Santos a partir da década de 1920, terá oferecido ao escritor sergipano material decisivo para a composição das personagens de Navios iluminados.

Nesse último aspecto, por sinal, valeria assinalar que mesmo a circunstância desde o primeiro momento sublinhada a propósito de haver em Cidade de Deus um "ponto de vista interno" - a expressão é de Roberto Schwarz na resenha famosa sobre o romance de Paulo Lins -, isto é, uma "identificação" entre o sujeito da enunciação e as diferentes vozes narrativas nela inscritas, poderia de algum modo ter sua contraparte no caso de Navios iluminados. Natural de Lagarto, no interior de Sergipe, Ranulfo Prata mais de uma vez se viu em trânsito entre cidades e regiões do país, do Nordeste para a capital da República, daí para o interior de São Paulo e de volta a Sergipe, até se fixar em Santos, cidade onde passou os quinze últimos anos de sua vida. Nesse sentido, a experiência de desgarramento e errância de tantos brasileiros, sobretudo nordestinos, cruzando-se com os percursos de outros tantos imigrantes estrangeiros, longe de ser objeto de escrutínio puramente estético ou intelectual, era em alguma medida parte da própria vivência do escritor.

E não será também fora de propósito atribuir a Navios iluminados, ainda que por simetria inversa, uma qualidade que Vilma Areas ${ }^{29}$ julga ver em Cidade de Deus: "uma profunda adequação entre o tema... e o ritmo ou andamento da prosa, que está em relação estreita com a vida do pobre, que apesar da movimentação, seja no batente, seja na ciranda da contravenção, literalmente não anda e nela nada acontece". Como já fizera Schwarz, Areas também sublinha o quanto a dinâmica da narrativa "desenvolvese em circuito fechado", o que, longe de fragilizar, daria corpo e potência ao livro de Paulo Lins, "pois ela dramatiza[ria] a cegueira e segmentação do processo". Em termos

29. Areas, Vilma. "Errando nas esquinas da Cidade de Deus". Praga: Revista de Estudos Marxistas. São Paulo, n. 5, pp. 43-53, jul. 1998. 
muito semelhantes, Alessandro Atanes Pereira ${ }^{30}$ afirmou a propósito do romance de Ranulfo Prata no bem realizado estudo que lhe dedicou:

É a própria narrativa de Navios iluminados que determina a escala microscópica. A trama apresenta seus personagens entre 1926 e o início da década seguinte, mas no livro não há qualquer menção a eventos históricos como a Revolução de $30 \mathrm{ou}$ o crash de 1929, que afetou consideravelmente as operações do porto de Santos. Ao invés do telescópio para observar as grandes movimentações econômicas e políticas do mundo, do país e até da cidade, Ranulpho Prata optou ele mesmo pela "escala reduzida da observação" da vida dos trabalhadores no bairro do Macuco (p. 11).

Ao que mais adiante acrescenta:

Esse isolamento é a chave da tragédia de José Severino de Jesus. Na cidade, ele é familiarizado apenas com o percurso entre sua casa e o cais; e evita fazer qualquer outro. São poucas e significativas suas saídas do bairro - a conquista do sonhado emprego na estiva, documentação de identidade, registro de casamento e internação no hospital. Severino até viaja de bonde em uma única vez, mas depois prefere ir a pé para economizar. O Macuco em torno do porto é seu universo. Nesse caso o bairro, mesmo traçado no mapa da cidade, é um território tomado pelo porto e sua atividade humana. A exploração narrativa desse espaço feita por Ranulpho Prata demarca esse isolamento (p. 78).

Tal insulamento, que se desdobra em múltiplos aspectos até o nervo central da própria angústia que assombra o protagonista, mas também na ausência de solução para os impasses representados na narrativa - aspecto assinalado por Luís Bueno na leitura que dele faz no seu Uma história do romance de $30-,^{31}$ ainda uma vez permitiria ver

30. Pereira, Alessandro Alberto Atanes. História e literatura no porto de Santos: o romance de identidade portuária Navios iluminados. 2008. Dissertação (Mestrado em História Social) - Faculdade de Filosofia, Letras e Ciências Humanas, Universidade de São Paulo, São Paulo, 2008. Disponível em: <http:// www.teses.usp.br/teses/disponiveis/8/8138/tde-30092008-145514/>. Acesso em: 10 jul. 2015.

31. Bueno, Luís. Uma história do romance de 30. São Paulo; Campinas: Edusp/Ed. da Unicamp, 2006, pp. 496-503. 
nessa obra de 1937 elementos de afinidade com a suspensão de juízo e o beco sem saída da espiral ascendente de violência do romance de 1997.

Mas nem tudo se reduz a essas afinidades. Se, no caso de Cidade de Deus, é possível reconhecer marcas do cinema de ação hollywoodiano, cujo potencial foi vigorosamente aproveitado na adaptação que o romance ganhou no começo da década passada, Navios iluminados é atravessado por uma difusa, mas persistente, ressonância chapliniana. Ela está na simpatia solidária e bem-humorada de Felício, na compaixão sofrida de Sá Generosa, na dignidade do desvalido Pato Tonto e, naturalmente, em mais de um aspecto da composição do protagonista do romance.

É notável, nesse sentido, a cena em que Severino, lutando para obter seu sonhado emprego nas Docas, vê-se em apuros diante da necessidade de tirar um retrato. Além de não ter dinheiro para pagar pelas fotos, o que acaba sendo contornado pela intervenção do amigo Felício, que logo lhe consegue um empréstimo com um conhecido, a própria experiência de ser fotografado constitui-se em desafio para Severino enfrentar. Toda a cena é construída em um tom que equilibra habilmente a representação do protagonista entre o ridículo e o comovente. Para economizar ao máximo, Severino faz a viagem do Macuco até a loja do fotógrafo no centro da cidade a pé, caminhada que no verão abrasador de Santos o deixa encharcado de suor, de tal modo que, lá chegando, "até os fundilhos da calça tinham uma larga mancha, parecendo que ele se sentara em uma poça d'água” (p. 63). Enquanto espera pelo retratista, seu olhar vaga pelos muitos retratos espalhados na saleta, que eram "[o]s mais variados possíveis. Caras de todos os jeitos: feias, bonitas, risonhas, trancadas, moças e velhas. Corpos em diferentes atitudes: em passo de dança, refestelados em poltronas, escorados em mesinhas floridas", até deter-se sobre um em especial: “... colorido, de uma mulher quase nua, envolta num véu que entremostrava a carne branca, [que] prendeu-lhe a atenção. Levantou-se e foi mirá-lo de perto, de nariz em cima. Achou-o uma beleza, assim misturado de cores".

Quando, por fim, o protagonista é posto pelo retratista "na posição oficial, de olhos postos na máquina assestada defronte", sente-se perturbado: "Severino, que nunca tirara retrato, estava confuso, de corpo duro, difícil de ser manejado pelas mãos do artista. Além de tudo, o calor da sala era muito, piorando a situação. Grossas gotas de suor desciam-lhe em rosário pela testa, pingando nas pálpebras que piscavam seguidamente, como se ele fosse atacado de um tique nervoso". Percebendo as dificuldades do freguês, o fotógrafo não muito simpático até essa altura da cena insta-o a manter-se firme, tomando com as mãos a cabeça de Severino para ajustar-lhe a posição e fazendo o comentário que irrita o já perturbado protagonista: “- Esta é das boas, é chata de 
verdade!". A cena, que poderia derivar para um confronto, se resolve com a frase apaziguadora do próprio retratista: “- Já quer brigar? Deixe disso, rapaz, estou caçoando. Eu também sou cabeça-chata, não está vendo? Sou da Paraíba”. Reconhecendo no antagonista, afinal, um confrade, ainda que distante, Severino consegue aprumar-se para a câmera e ser, afinal, fotografado.

O episódio ainda se desdobra no dia seguinte com a retirada das fotografias, nas quais Severino, agora diante dos "retratinhos de polegada", cujas cópias examina cuidadosamente "como se fossem diferentes", vai experimentar a um tempo o reconhecimento e a estranheza de si mesmo, já transformado nessa trajetória cheia de percalços a que se lançara desde a vinda de sua longínqua cidade nordestina, com uma gravata mal-ajambrada, cabelos despenteados, fisionomia feia e magra, tão diversa da imagem de si que podia evocar nas lembranças de Patrocínio do Coité: "de Raimunda, da mãe e dos irmãos, ficando um pedaço a pensar neles, os retratos nas mãos, os olhos no chão e uma saudade aguda na alma".

Toda a cena faz pensar nas formulações de Walter Benjamin a propósito das relações entre homem e máquina no âmbito das tecnologias de reprodução midiática:

O intérprete do filme não representa diante de um público, mas diante de um aparelho. O diretor ocupa o lugar exato que o controlador ocupa num exame de habilitação profissional. Representar à luz dos refletores e ao mesmo tempo atender às exigências do microfone é uma prova extremamente rigorosa. Ser aprovado nela significa para o ator conservar sua dignidade humana diante do aparelho..$^{32}$

Se as pequeninas imagens que reproduzem a modesta efígie de Severino não parecem capazes de resgatar-lhe sua humanidade, ao menos a cópia escolhida pelo funcionário do recrutamento, nos informará o narrador, "era [a] melhor, [a] mais bem-parecida".

As experiências do protagonista nos primeiros ofícios nas Docas, nas oficinas da Mortona ou nas barcaças de dragagem do Estuário mais de uma vez mostram o quanto essa personagem, mesmo acossada por toda sorte de atribulações, é capaz de refletir sobre sua condição e projetar-se mais além, na esfera do desejo. As personagens

32. Benjamin, Walter. "A obra de arte na era de sua reprodutibilidade técnica". In: Obras escolhidas: Magia e técnica, arte e política. Ensaios sobre literatura e história da cultura. Tradução de Sergio Paulo Rouanet. São Paulo: Brasiliense, 1985, v. 1, p. 175. 
pobres, que dominam o romance, são consistentemente caracterizadas, nos limites de suas circunstâncias, como capazes de introspecção, reflexão e sonho. Para dar conta disso, o autor mobiliza uma variedade de procedimentos por meio dos quais compõe com grande habilidade essa riqueza de tons.

Veja-se, por exemplo, a cena em que, pelas mãos de Felício, o protagonista é apresentado ao chefe político por meio do qual conseguirá ingressar nas Docas. A essa altura do romance, o leitor já tem notícia de toda a trajetória que levara Severino a tentar a sorte na cidade portuária. Nas entrelinhas do diálogo entre Severino e o doutor Constantino, temos acesso a uma complexidade que não tem como emergir nas circunstâncias da cena, e justamente pelo silêncio permite o contraponto com relação a toda uma série de clichês das classes mais abastadas quanto à imprevidência ou falta de discernimento dos mais pobres:

- De que cuidava por lá?

- Plantava uma nesguinha de terra.

- E então, se possuía alguma coisa, para que saiu?

Severino engasgou. Era uma resposta difícil de dar. Difícil e comprida. Limitou-se a dizer simplesmente:

- Não via vantagem.

O doutor disse baixo, parecendo que só para ele: - É uma contingência danada.

Outro exemplo dessa delicada e eficaz composição do protagonista aparecerá logo após o seu ingresso nas Docas. Diante da complexidade do maquinário nas oficinas, na hora do lanche, Severino busca "tomar fé do lugar onde estava", tentando traduzir o maquinário da grande forja em termos de sua experiência prévia e familiar: "[Era] por certo muito diferente do fole de seu Roque, ferreiro de Patrocínio, cujo fogo era alimentado a braço".

Também nos momentos livres nas tarefas da barcaça de dragagem, no esforço de rememoração das experiências prévias e da tentativa de interpretação de sua nova condição, sua consciência vai ganhando corpo, na cena notável que fecha o sexto capítulo:

Severino, apesar de cansado, não tinha sono. Estirou-se no convés, acendeu um cigarro e ficou a olhar as águas escuras do canal, e, do outro lado, as luzes de Itapema e Guarujá. Em torno, as sombras silenciosas dos outros batelões. Ele olhava para tudo, mas o pensamento estava longe, em Patrocínio. De quando em quando soltava um suspiro fundo, 
que repercutia no silêncio da embarcação. Virando os olhos para o alto, reparou no céu todo cravejado de estrelas, muito vivas, iguaizinhas às que costumava admirar deitado no terreiro de sua casa, de papo para cima, nas noites quentes. Porque sempre gostou de fitar o céu noturno. Achava, naquelas pequenas tochas perenes, uma beleza misteriosa que o atraía, fazendo-o trabalhar com o juízo e pensar: "Se pelo avesso é assim, que dirá pelo direito".

De súbito, surgiu sobre as águas um imenso clarão. Um transatlântico passava, gigantesco, vagarosamente. Ia tão iluminado que parecia levar todas as estrelas do céu...

Severino, numa fascinação de quem via aquilo pela primeira vez, acompanhou-o com a vista até ele desaparecer de todo na curva do canal.

A marola formada pelo sulco do enorme barco batia forte no casco do Valongo.

O domínio dos procedimentos narrativos, somado à maneira delicada por meio da qual Ranulfo Prata compõe suas personagens, fugindo a esquematismos facilitadores, resulta num quadro de complexidade que se afasta dos estereótipos: entre os trabalhadores, há gente solidária e animosa como Felício, assim como os duros feitores das oficinas das Docas - temos estrangeiros otimistas e aventurosos, ao lado de outros egoístas e conformados, temos sindicalistas pelegos, mas também aqueles que se dedicam vigorosamente às causas de sua classe. Temos médicos insensíveis ao sofrimento de seus pacientes, mas também aqueles que, em face do inevitável, se empenham em atenuarlhes o sofrimento. E uma mesma personagem acumula aspectos contraditórios.

O tratamento dado ao espaço na construção dessa narrativa, para além da eficácia alcançada em termos de arquitetura ficcional - a já referida concentração em circuitos estreitos e fechados na circulação das personagens -, parece de algum modo refletir certa afetividade na atenção aos detalhes da paisagem urbana santista. Se isso vale para as menções a logradouros e espaços referenciais para a cidade, como o restaurante Chave de Ouro ou a sede do Sindicato dos Estivadores, fica particularmente notável no caso do mais característico referencial topográfico da área central da cidade: o monte Serrat. Se é certo que ele entra na narrativa por conta do dado verista, já que em uma de suas encostas - o chamado "Morro do Fontana" - é que se localizava o hospital de isolamento no qual o protagonista passará uma temporada perto do final da narrativa, essa posição fronteiriça entre a região central da cidade, associada à vida áspera dos trabalhadores do porto, e a área oposta na geografia urbana santista, representada pelo balneário praiano frequentado pela gente abastada, será bem explorada em termos narrativos no capítulo XXI. No alto do monte Serrat funcionava desde 1927 
um cassino, cujos sons ruidosos, "pingando luz pelos beirais e cornijas, incomodavam demais [os pacientes]" (p. 265). Contudo, ao referir-se ao cassino, o narrador não deixa de registrar o detalhe documental: "Ao lado do pavilhão [do hospital de isolamento], o monte Serrat, com sua ferida no flanco e o cassino trepado no cocuruto, tapando a vista da igrejinha que Severino tanto queria olhar, sabedor de seus milagres" (p. 265).

De fato, logo após a entrada em funcionamento do cassino, chuvas torrenciais no fim do verão de 1928 produziram um grande deslizamento de toda uma aresta do morro, cuja contenção posterior foi feita por meio de uma enorme estrutura em concreto cobrindo toda uma face da encosta, a tal "ferida no flanco". É notável, porém, o quanto tal referência territorial verista funciona como ressonância do sofrimento da gente pobre no pavilhão de isolamento da Santa Casa, em face dos endinheirados que desfrutavam das festas e jogos no topo da cidade. O mesmo morro já aparecera antes, de relance, a compor a paisagem da gente do Macuco que madrugava no inverno santista: "O monte Serrat tinha na cabeça um turbante de bruma" (p. 179).

Essa combinação entre atenção verista, eficácia ficcional e afetividade na representação do espaço urbano serão decerto ressonâncias de Lima Barreto, um dos mentores de Ranulfo Prata em seus primeiros passos na ficção.

Uma última palavra sobre a edição. Muito bem cuidado em seus aspectos visuais e quanto ao estabelecimento do texto, o volume acrescenta ainda, além de uma breve nota editorial prévia, uma apresentação de Marisa Deaecto e um pós-escrito de José de Paula Ramos com notícias sobre a trajetória do escritor e uma útil fortuna crítica sobre sua produção. Contudo, embora a edição tenha como público-alvo, em princípio, "o leitor em formação", as notas explicativas que se acumulam ao longo do volume, por vezes, parecem subestimar o público. Ao lado de explicações sobre certos termos hoje menos comuns ou que eram gíria mais ou menos habitual no cais santista à época em que o romance se ambienta, acumulam-se informações ociosas como a da nota 4 na página 31, que informa que "terremoto de Lisboa" refere ao "grande terremoto, seguido de tsunami, que arrasou a capital de Portugal em 1755", ou aquela que, na página 128, informa que "terra de seu Cabral" é "perífrase para Brasil", acrescentando ainda tratarse de "referência a Pedro Álvares Cabral (1468?-1520), navegador português ao qual se atribui o descobrimento do Brasil".

Embora se acumulem notas informativas quanto à Companhia Docas de Santos (p. 28), quanto ao jornal santista $A$ Tribuna (p. 31), sobre a Companhia de Navegação Lloyd Brasileiro (p. 38), e até mesmo sobre Thomas Morton, engenheiro a quem se deveria a criação das mortonas, doca seca para reparos navais, todas elas com datas e 
detalhes enciclopédicos, nenhuma nota é aberta para dar qualquer notícia do sindicato dos trabalhadores das Docas, que aparece em mais de um momento do romance e no qual atuam, entre outros personagens como Felício, Valentim e Pepe. Do ponto de vista editorial, uma reavaliação das notas, enxugando-as e equilibrando seu perfil, poderia ser considerada, fazendo justiça ao cuidado dedicado a todos os demais aspectos dessa publicação.

Voltando ao mote inicial destes apontamentos, a peculiar sensação de familiaridade que um leitor de hoje experimenta ao final desse belo livro de Ranulfo Prata, a despeito dos mais de setenta anos que nos separam de sua publicação original, é a um tempo prazerosa e perturbadora: se é verdade que o romance de Ranulfo Prata como também a obra mais recente de Paulo Lins não apontam para soluções em face da matéria que buscam representar, é certo que, no romance de 1937, mais de uma vez seremos alertados para o fato de que o dinheiro, que tudo controla e cuja escassez sela o destino de todos, não é um valor absoluto: personagens como Pato Tonto, Felício, Sá Generosa e o próprio Severino dão forma aos matizes do desejo radicalmente humano de meditar, sonhar e amparar os seus afetos pelo tempo que for possível. Ao passarmos aos bichos-soltos de Cidade de Deus, temos uma ampla conversão dessas aspirações humanas em pulsões impetuosas e regressivas de legiões de "sujeitos monetários sem dinheiro".

Com habilidade e delicadeza, Ranulfo Prata parece pôr em questão, já lá em 1937, com seu tão injustamente desconhecido romance, as melhores esperanças cultivadas por gerações de artistas nas décadas que se seguiram. Lido em nossos dias, Navios iluminados nos adverte para o fato de que nem todos os abismos serão navegáveis a barquinhos de papel.

Benito Martinez Rodriguez é professor de literatura brasileira na Universidade Federal do Paraná. 